\title{
Estratégia enquanto prática e os lapsos conceituais
}

\author{
Strategy as practice and the conceptual short comings
}

Valdete Noveli Rhoden

Mestre em Administração pelo Programa de Pós-Graduação em Administração da Pontifícia Universidade Católica do Paraná (PPAD/PUCPR), Curitiba, PR - Brasil, e-mail: vnrhoden@yahoo.com.br

\section{Resumo}

0 artigo apresenta e discute as principais limitações da área strategy as practice como sendo parte de um fenômeno histórico de várias vertentes epistemológicas no estudo das organizações, especificamente nos estudos sobre estratégias. A estratégia enquanto prática considera como foco de estudo o que as pessoas fazem e com que resultados. Esta visão baseada na atividade abre uma oportunidade de pesquisa comparativa com alguns conceitos relativos à estratégia, que ocupa grande espaço na literatura, e que explicita as limitações no entorno dos estudos da disciplina em questão. Buscou-se com esse ensaio situar e delinear a área da estratégia nas pesquisas, através de um levantamento bibliográfico. Esse levantamento abrangeu tanto o conceito de "estratégia enquanto prática" como as teorias que tiram a força desse conceito. Na sequência, apresenta-se uma estrutura analítica que possa contribuir com as pesquisas em estratégia e com a construção de conceitos nessa área. Considera-se um viés sociológico de ações, estabelecendo-se uma linha tênue com os resultados encontrados na pesquisa bibliográfica acerca do tema estratégia.

Palavras-chave: Estratégia. Prática. Lapsos. Paradigmas.

\section{Abstract}

This paper presents and discusses the main weaknesses of the practice area strategy as part of a historical phenomenon of several strands in epistemological study of organizations, specifically in studies of strategies. The strategy as a practice considered as the focus of study, what people do and with what results. This vision-based activity provides an opportunity for comparative research with some concepts related to strategy, which occupies a large space in the literature, which explains the limitations of the studies in the vicinity of the discipline in question. We sought to test this with both, place and outline the strategy in the area of research through a literature review. This survey covered both the concept of "strategy as practice" as the theories that take the strength of that concept. Following, we present an analytical framework that can contribute to the research strategy and the 
construction of concepts in this area is considered a sociological view of action, establishing a fine line with the findings in the literature on the subject strategy.

Keywords: Strategy. Practice. Lapses. Paradigms.

\section{Introdução}

Ao se pesquisar a literatura sobre estratégia, observa-se quantas formulações de pensamentos se podem presenciar e uma dimensão preocupante acerca de um lapso conceitual que precisa ser entendido e sanado. Segundo Denis, Langley e Rouleau (2006), o pluralismo nos estudos em estratégia gera uma nulidade que, não raro, tenta-se que seja suprida pelo "poder dos números". Muito já se fez neste sentido, mas ainda há espaço para contribuições significativas. Pela pesquisa bibliográfica, percebe-se que ainda é necessário um esforço acerca da reformulação dos pensamentos pragmático e fenomenológico.

É devido a esse desacordo teórico endêmico que a ciência social se divide em tradições e escolas. Esses grupos solidários não são simplesmente manifestações de desacordo científico, mas bases sobre as quais tais desacordos são promovidos e mantidos. Ritzer (1975) defende a existência de um paradigma múltiplo no estudo da teoria das organizações como sendo "a imagem fundamental de um assunto dentro da ciência, que serve para diferenciar uma comunidade de estudiosos de todas as outras". Em outras palavras, implica em que diferentes cientistas de uma mesma área detêm diferentes imagens sobre a natureza essencial do fenômeno estudado. Em vez de considerar o desacordo e a comunicação distorcida que o acompanha como um mal necessário e que deva ser resolvido, muitos teóricos tomam o conflito entre escolas como indicador do caráter saudável de uma disciplina. Pergunta-se, então, qual a dimensão dessa postura no século XXI e até que ponto a falta de um consenso torna-se nociva para as organizações e o meio acadêmico.

De outro lado, estão autores que buscam quebrar antigos paradigmas mostrando um compromisso indissolúvel com o objeto de estudo. Por exemplo, Doz e Prahalad (1991) argumentaram em favor da busca de um novo paradigma para o campo de estudos em estratégia, em função do crescente reconhecimento do declínio na contribuição de velhos conceitos e ferramentas de análise. Os autores esclarecem também a necessidade de maior aproximação de pesquisadores com o trabalho efetivo dos estrategistas e ressaltam a preocupação em torno dos desenvolvimentos da prática gerencial, principalmente ao entender o resultado do trabalho da cúpula estratégica e o desempenho global das organizações como elementos indissociáveis (DOZ; PRAHALAD, 1988). A próxima seção tentará expor com clareza as principais diferenças teóricas nos estudos em estratégias.

\section{Revisão da literatura}

A pesquisa literária busca situar a temática proposta no contexto das principais publicações acerca do tema estratégia, a fim de estabelecer uma relação de coerência com a importância da proposição levantada já no título do presente trabalho.

\section{Conceitos e dilemas teóricos sobre estratégia}

A palavra estratégia vem do grego strategos e significa literalmente "general". Na literatura sobre administração, porém, seu significado extrapola o conceito simplista de base militar. Segundo a opinião de vários autores a estratégia é considerada um conjunto de regras de tomada de decisão para a orientação do comportamento de uma organização e que envolve padrões, processos e metas. Nesse contexto, a estratégia tem sete características específicas e seu conceito é abstrato: 1) as estratégias nem sempre resultam em ações imediatas, assim, 2) a estratégia deve gerar projetos estratégicos por meio de um processo de busca; 3 ) a estratégia é desnecessária quando historicamente a dinâmica organizacional a leva aonde ela quer ir (objetivo); 4) a estratégia baseia-se em informações agregadas, incompletas e incertas sobre as alternativas disponíveis; 5) o uso apropriado da estratégia exige "feedback estratégico", ou seja, tanto a escolha quanto o resultado da decisão devem gerar o mínimo ou nenhuma dúvida; 6) os objetivos são os fins e a estratégia é o meio para se atingir os 
fins; e 7) as estratégias e os objetivos são intercambiáveis, ou seja, há uma relação hierárquica: os elementos da estratégia num nível gerencial mais elevado transformam-se em objetivos em níveis mais baixos.

Não se pode deixar também de observar a divergência entre autores quando dizem que a estratégia é desnecessária se historicamente a dinâmica organizacional a leva aonde ela quer ir. Como são tanto as análises internas como externas para que a estratégia funcione, estudos em livros levam ao fato de que empresas de renome e historicamente com alto desempenho, como IBM, HP e Compaq, não acreditaram na estratégia da Dell de vender computadores pessoais diretamente aos especialistas e clientes corporativos. Esses concorrentes apostavam que o mercado não absorveria um alto custo de substituição e estavam enganadas, pois a Dell oferecia baixos custos. Assim, os acordos com os canais de distribuição impediram os concorrentes da Dell de colocar em prática as estratégias de combate.

Porter (1996) afirma que o benchmarking é destrutivo por gerar imitação de técnicas e convergindo para as mesmas estratégias e o mesmo percurso, sem um vencedor. Assim, uma organização consegue destacar-se de outra ao oferecer ao mercado uma vantagem competitiva quando o conjunto de suas atividades, e não apenas algumas, contribuem para isso.

Ainda segundo Porter (1996), a estratégia é a criação de uma posição única e valiosa, que engloba um conjunto diferente de atividades (conhecida como diferenciação). Se houvesse apenas um posicionamento ideal, a estratégia não seria necessária. A essência do posicionamento estratégico é o de escoIher atividades diferentes das dos rivais. Nesta abordagem, se o mesmo conjunto de atividades fosse o melhor para produzir todo o tipo de variedades, de satisfazer todas as necessidades e de ter acesso a todos os consumidores; então as empresas poderiam facilmente substituir-se entre si e a eficiência operacional determinaria os resultados. Esse conceito se apresenta vago e suscetível à vulnerabilidade de críticas de outros autores. Por exemplo, Aktouf (2002) diz que Porter, no núcleo de sua argumentação comete diversos e "graves erros" ideológicos, metodológicos e epistemológicos. Nessa abordagem, Porter desconsidera as numerosas posições aristotélicas e pós-aristotélicas quanto à importância humana na atividade econômica. Ao associar a estratégia de diferenciação com a vantagem competitiva, ele restringe a primeira, já que uma estratégia bem-sucedida pode ser propositalmente copiada por outra organização.

Whittington (2003) fundamenta sua teoria argumentando que a estratégia é alcançada pelo trabalho de agentes de alto conhecimento, ou seja, a estratégia emerge da atividade gerencial, onde os gestores se esforçam rotineiramente em algo que seja formal, analítico e sistemático. Fazem isso através do ciclo de planejamento estratégico. Para o autor, estratégia é algo que as pessoas "fazem" e não algo que a organização "tem". Quanto mais a estratégia se aproxima da prática, mais se percebe que ela não é um atributo da organização, antes, é um reflexo da atividade dos indivíduos, ou um fenômeno social (WHITTINGTON, 2006, p. 617). 0 autor propõe que se estude como são produzidas as práticas, que não seria possível, pois haveria de se estudar as mais profundas motivações, adentrando a psicologia. Por ora, parece que o autor chegou ao mesmo ponto de onde Mintzberg partiu quando iniciou seus estudos sobre processos estratégicos, que será tratado à frente.

Ao se examinar o trabalho de Jarzabkowski, Balogun, Seidl (2007), percebe-se ainda que surgem novos termos para explicar algo já explicado por outros autores (por exemplo, práxis como sendo toda atividade humana). Na abordagem desta autora, a estratégia é um tipo particular de atividade ligada com práticas particulares. É um campo particularmente suscetível de ser multiníveis (JARZABKOWSKI, 2003). Nesse último conceito percebe-se uma clara aproximação conceitual entre estratégia e prática. Observa-se uma convergência nas ideias principais desta autora com as de Whittington.

Em outro artigo, Whittington (2003) aponta as falhas nos estudos sobre estratégia tendo como foco central os riscos envolvidos no discurso. Para os autores, o discurso pode ofuscar os estudos porque pode não refletir a realidade e considera pessoas e "identidades" no processo. Utiliza-se aqui o próprio argumento dos autores para enfatizar a necessidade de aproximação dos estudiosos com a realidade. Foi exposto o caso da Enron, uma organização que chegou a ser a sétima maior empresa norte-americana trabalhando em muitos campos de energia não relacionados ao petróleo. Para os autores, o caso da falência da Enron faz pensar sobre como o discurso pode ser enganador (visto nesse ângulo pelos autores como uma estratégia). Talvez seja apenas uma questão semântica ou de ética mesmo, já que, no caso da Enron, tratou-se de uma fraude nos registros contábeis. Neste 
caso, se o fenômeno chamou-se estratégia ou prática não importa muito. Mais importante que o conceito é estar dentro da lei, até porque supostamente a ciência trabalha no limite desta. Talvez esse não seja um bom exemplo para se teorizar.

Mintzberg (1975) inaugura uma corrente de pesquisa com a atenção voltada fundamentalmente para a ação. 0 principal benefício dessa vertente para o campo acadêmico parece ter sido a extensão do lócus da ação estratégica, intencionalmente orientada ou não, para os atores da organização como um todo. Desde então, a estratégia não se restringe ao alto escalão da organização (MINTZBERG, 1975). A partir da referenciada obra, Mintzberg pesquisa a formação do processo de estratégia, baseando-se na estratégia como padrão de "sucessão" de decisões (neste caso excetua-se a estratégia emergente). Para o autor, estratégia significa pensar no futuro, uma perspectiva. A formação de estratégia é um processo de planejamento, idealizado ou apoiado por planejadores, para produzir planos. Mais à frente, aponta-se o falso dualismo entre formulação e implementação e verifica-se que a estratégia pode simplesmente formar-se de maneira espontânea a partir da convergência de comportamento de atores (MINTZBERG; McHUGH, 1985). Mintzberg mostra os lapsos da teoria de Whittington antes mesmo desta existir.

Partindo-se do pressuposto de que para tudo há uma lógica, uma razão, Mintzberg propõe e discorre sobre a operacionalização da estratégia (decomposição em subestratégias - se a decomposição for feita corretamente todas essas tarefas individuais se somarão para realizar as intenções estratégicas globais das organizações (MINTZBERG, 2004). Percebe-se aqui o foco nas tarefas estratégicas $a$ priori e não a posteriori como propõem os autores da estratégia enquanto prática. Resumindo em 5Ps, a estratégia tem as seguintes características, conforme Mintzberg, Lampel e Ahsltrand (2000): 1) é uma posição; 2) um padrão; 3) é uma perspectiva; 4) é um ploy (truque) e 5) um plano.

Para efeito deste trabalho, adota-se a estratégia como sendo escolhas feitas pelas organizações, que normalmente são duradouras. Ela é considerada como uma configuração que combina ou dá ênfase a determinados atributos em detrimento de outros, para lidar com o contexto ambiental percebido. A estratégia nesse contexto trata de mudanças com um plano deliberado.
A crítica de Mintzberg às escolas

do pensamento estratégico

A obra de Mintzberg é apenas um exemplo do universo crítico da literatura em administração. A literatura é ampla e complexa tal qual seu objeto de estudo (MINTZBERG; LAMPEL; AHSLTRAND, 2000, p. 15). O Quadro 1 apresenta um resumo da abordagem crítica de Mintzberg acerca das escolas de pensamento. As três primeiras são: escola do design, do planejamento e do posicionamento. A literatura e as escolas de administração se encarregaram de consagrar essas três escolas, fortemente influenciadas por Porter (1986), que se baseiam em fases distintas de formulação, implementação e controle, executadas em etapas quase em cascata. Daí o caráter racional prescritivo. Em um segundo grupo estão as seis escolas de caráter descritivo que se concentram no processo de concepção da estratégia: escola empreendedora, cognitiva, de aprendizado, de poder, cultural e ambiental. A última escola, a de configuração, procura integrar várias partes da organização em função de diferentes estágios do seu ciclo de vida. Ela apresenta uma perspectiva conciliadora das demais escolas. Em síntese, as dez escolas buscam sistematizar e integrar as várias concepções e processos que envolvem a formulação e implementação de estratégias. A intenção do artigo é despertar o leitor para o foco das divergências epistemológicas em vez de aprofundar em cada conceito.

Na obra crítica das dez escolas (MINTZBERG; LAMPEL; AHSLTRAND, 2000) encontraram uma metodologia própria para defender suas abordagens sobre estratégia. Em seu discurso, estão presentes o poder de síntese e a coragem para apontar os lapsos que esse artigo se propôs a pesquisar, entre outros. Fez mais do que isso: apontou as contribuições de cada escola. Assim, a posição adotada possivelmente influencie outros pesquisadores. Infelizmente fica claro o real cenário de divergências conceituais que implicam diretamente nas estratégias organizacionais que estão no mundo real (MINTZBERG; LAMPEL; AHSLTRAND, 2000, p. 93), que apresenta o caso da Honda Motorcycle.

Em seu livro $O$ que é Estratégia, Richard Whittington expõe sua opinião de que o conceito de estratégia se perdeu e ele próprio também devido a várias abordagens e à teoria crítica. Mintzberg argumenta uma questão fundamental pendente relacionada à comprovação de soluções de "algum problema estratégico" antes de falar em conceito global. 
Quadro 1 - Resumo da crítica de Mintzberg às escolas do pensamento estratégico

\begin{tabular}{|c|c|c|c|}
\hline Escola & $\begin{array}{l}\text { Ênfase da } \\
\text { Formulação da } \\
\text { estratégia }\end{array}$ & Principais Autores & Crítica de Mintzberg \\
\hline Design & $\begin{array}{l}\text { Como um processo } \\
\text { de concepção. }\end{array}$ & $\begin{array}{l}\text { Selznick (1957), Chandler (1962); } \\
\text { Learned et al. (1965). }\end{array}$ & $\begin{array}{l}\text { A estrutura segue a estratégia assim como } \\
\text { o pé direito segue o esquerdo, ou seja, é } \\
\text { uma questão de lógica e não de teoria. Não } \\
\text { é possível separar formulação de implemen- } \\
\text { tação. }\end{array}$ \\
\hline Planejamento & $\begin{array}{l}\text { Como um processo } \\
\text { formal. }\end{array}$ & $\begin{array}{l}\text { Ansoff (1965), Ackoff (1983), } \\
\text { Lorange (1980), Porter (1980), } \\
\text { Schendel e Hofer (1979), Porter } \\
(1980,1985) .\end{array}$ & $\begin{array}{l}\text { A determinação e a formalização são uma } \\
\text { falácia e a análise de dados, via de regra, é } \\
\text { distante da realidade. }\end{array}$ \\
\hline Posicionamento & $\begin{array}{l}\text { Como um processo } \\
\text { analítico. }\end{array}$ & $\begin{array}{l}\text { Influência de Porter (1980, 1985); } \\
\text { Clausewitz (1989), Quinn (1980). }\end{array}$ & $\begin{array}{l}\text { Mintzberg diz que ela pode ser criticada } \\
\text { pelos mesmos motivos que as escolas de } \\
\text { design e planejamento, mas destaca: foco } \\
\text { (econômico), contexto (propensão para o } \\
\text { grande), processo (números) e estratégia } \\
\text { em si (posição genérica). }\end{array}$ \\
\hline $\begin{array}{l}\text { Empreende- } \\
\text { dora }\end{array}$ & $\begin{array}{l}\text { Como um processo } \\
\text { visionário. }\end{array}$ & $\begin{array}{l}\text { Schumpeter (1950), Cole (1959), } \\
\text { McClelland (1961), Baumol (1968), } \\
\text { Pinchot (1985), Stevenson e } \\
\text { Gumpert (1985), Busenitz e Barney } \\
\text { (1997). }\end{array}$ & $\begin{array}{l}\text { É necessário definir o papel e temporalidade } \\
\text { da visão. A formação da estratégia não é } \\
\text { calcada no comportamento de um indivíduo } \\
\text { apenas. }\end{array}$ \\
\hline
\end{tabular}

$\begin{array}{llll} & \text { Como um processo } & \text { Meyers (1962), Kiesler (1971), Janis } & \\ \text { Cognitiva } & \text { (1972), Simon }(1947,1957), \text { Huff } & \text { Provoca confusão pelas suas analogias e } \\ & \text { mental. } & (1990) . & \text { metáforas. }\end{array}$

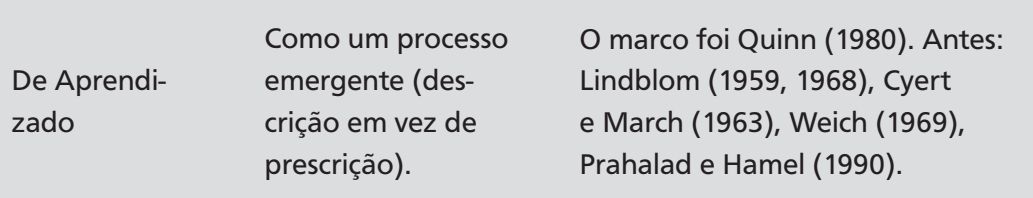

\begin{tabular}{llll}
\hline & & Allison (1971): micro, Pfeffer e & Exagero nas colocações. A formação da es- \\
Do Poder & $\begin{array}{l}\text { Como um processo } \\
\text { de negociação. }\end{array}$ & $\begin{array}{l}\text { Salancik (1978), Astley (1984): } \\
\text { macro. }\end{array}$ & $\begin{array}{l}\text { tratégia é um processo destituído de poder } \\
\text { e política. }\end{array}$
\end{tabular}

Como um processo

Cultural coletivo - interação social.

Rhenman e Normann (final dos anos 1960), se nenhuma outra fonte mencionada por Mintzberg.
Misturou a teoria com as das escolas prescritivas.

$\begin{array}{llll} & \text { Como um processo } & \text { Hannan e Freeman (1977) e teó- } & \\ \text { Ambiental } & \begin{array}{l}\text { reativo, visão de } \\ \text { contingência. }\end{array} & \begin{array}{l}\text { ricos de contingência no final dos } \\ \text { anos 1960. }\end{array} & \begin{array}{l}\text { As dimensões de ambiente são vagas, abs- } \\ \text { tratas e agregadas. }\end{array}\end{array}$

Falta de clareza conceitual. Caracteriza as mudanças como sendo difíceis. Favorece a administração da consistência e tradição. 
Quadro 1 - Resumo da crítica de Mintzberg às escolas do pensamento estratégico

\begin{tabular}{|c|c|c|c|}
\hline Escola & $\begin{array}{l}\text { Ênfase da } \\
\text { Formulação da } \\
\text { estratégia }\end{array}$ & Principais Autores & Crítica de Mintzberg \\
\hline De configuração & $\begin{array}{l}\text { Como um processo } \\
\text { de transformação. } \\
\text { Enfoque em dois } \\
\text { aspectos: } 1 \text { ) estados } \\
\text { da organização e } \\
\text { do contexto como } \\
\text { configurações e 2) } \\
\text { processo de geração } \\
\text { da estratégia como } \\
\text { transformação. }\end{array}$ & $\begin{array}{l}\text { Miller e Friesen (1980, 1982, 1984), } \\
\text { Pettigrew (1987, 1996), Mintzberg, } \\
\text { Ahlstrand e Lampel (2000). }\end{array}$ & $\begin{array}{l}\text { Minzberg, Miles, Miller (final dos anos 1970), } \\
\text { Miles e Snow (1978). Não foca críticas a esta } \\
\text { escola. Apenas rebate as críticas feitas por } \\
\text { Donaldson (1996). }\end{array}$ \\
\hline
\end{tabular}

Fonte: a partir de MINTZBERG; LAMPEL; AHSLTRAND, 2000.

Quadro 2 - Alguns conceitos e características de estratégia

(continua)

\begin{tabular}{|c|c|c|c|c|}
\hline Escola & Ênfase da Formulação da estratégia & Principais Autores & $\begin{array}{l}\text { Crítica de } \\
\text { Mintzberg }\end{array}$ & $\begin{array}{l}\text { Proc. Rac./ } \\
\text { Analítico }\end{array}$ \\
\hline Chandler (1962) & $\begin{array}{l}\text { É a determinação dos objetivos básicos de longo } \\
\text { prazo de uma organização e adoção de ações } \\
\text { adequadas e alocação de recursos para se chegar } \\
\text { aos objetivos. }\end{array}$ & $\begin{array}{l}\text { Objetivos } \\
\text { Meios } \\
\text { Alocação de recursos }\end{array}$ & $\begin{array}{l}\text { O mais alto } \\
\text { nível de de- } \\
\text { cisão }\end{array}$ & \\
\hline $\begin{array}{l}\text { Learned et al. } \\
\text { (1965), Andrews } \\
\text { (1971) }\end{array}$ & $\begin{array}{l}\text { É o padrão de objetivos fins ou metas e principais } \\
\text { políticas e planos para atingir esses objetivos } \\
\text { estabelecidos, de forma a definir qual o negócio } \\
\text { em que a organização está, o tipo que é ou será. } \\
\text { A Escola de Design prega a estratégia simples, } \\
\text { criativa e informal. }\end{array}$ & $\begin{array}{l}\text { Objetivos } \\
\text { Meios }\end{array}$ & $\begin{array}{l}\text { A estratégia } \\
\text { emerge da } \\
\text { liderança } \\
\text { formal }\end{array}$ & $\begin{array}{l}\quad \text { X } \\
\text { Nem } \\
\text { sempre há } \\
\text { formali- } \\
\text { zação do } \\
\text { processo }\end{array}$ \\
\hline $\begin{array}{l}\text { Ansoff (1965), } \\
\text { Ansoff e } \\
\text { McDonnel } \\
\text { (1993) e Ansoff } \\
(1990)\end{array}$ & $\begin{array}{l}\text { É um conjunto de regras de tomada de decisão } \\
\text { para orientar o comportamento da organização, } \\
\text { em condições de desconhecimento parcial. O } \\
\text { conceito é abstrato e atende sete características } \\
\text { específicas. Ansoff instaurou o modelo de "casca- } \\
\text { ta de decisões". Estrutura conceitual "global". }\end{array}$ & $\begin{array}{l}\text { Meios } \\
\text { Produtos e mercados } \\
\text { Vetores do cresci- } \\
\text { mento } \\
\text { Vantagem competi- } \\
\text { tiva } \\
\text { Sinergia }\end{array}$ & $\begin{array}{l}\text { Conselho de } \\
\text { Administração }\end{array}$ & $x$ \\
\hline $\begin{array}{l}\text { Steiner e Miner } \\
\text { (1977) }\end{array}$ & $\begin{array}{l}\text { É forjar das missões da organização estabele- } \\
\text { cimento de objetivos à luz de forças internas e } \\
\text { externas, formulação de políticas específicas e } \\
\text { estratégias para atingir objetivos e assegurar a } \\
\text { implementação. }\end{array}$ & $\begin{array}{l}\text { Objetivos } \\
\text { Meios }\end{array}$ & $\begin{array}{l}\text { Ponto de vista } \\
\text { do dirigente } \\
\text { máximo }\end{array}$ & $x$ \\
\hline Porter (1980) & $\begin{array}{l}\text { Estratégia competitiva: são ações ofensivas ou } \\
\text { defensivas para criar uma posição única, competi- } \\
\text { tiva e valiosa numa indústria, a fim de obter mais } \\
\text { retorno do investimento. }\end{array}$ & & Administração & $x$ \\
\hline
\end{tabular}


Quadro 2 - Alguns conceitos e características de estratégia

(conclusão)

\begin{tabular}{|c|c|c|c|c|}
\hline Escola & Ênfase da Formulação da estratégia & Principais Autores & $\begin{array}{l}\text { Crítica de } \\
\text { Mintzberg }\end{array}$ & $\begin{array}{l}\text { Proc. Rac./ } \\
\text { Analítico }\end{array}$ \\
\hline Quinn (1980) & $\begin{array}{l}\text { É um modelo ou plano que integra objetivos, po- } \\
\text { líticas e a sequência de ações num todo coerente. } \\
\text { Introduziu a ideia de incrementalismos lógico e } \\
\text { cognitivo. }\end{array}$ & $\begin{array}{l}\text { Objetivos } \\
\text { Meios }\end{array}$ & & $\mathrm{X}$ \\
\hline $\begin{array}{l}\text { Mintzberg } \\
(1985), \\
\text { Mintzberg } \\
\text { (1988a) }\end{array}$ & $\begin{array}{l}\text { A estratégia é formada a partir de vários proces- } \\
\text { sos complexos. É uma força mediadora entre a } \\
\text { organização e o seu meio envolvente: um padrão } \\
\text { no processo de tomada de decisões organizacio- } \\
\text { nais para fazer face ao ambiente. }\end{array}$ & & & \\
\hline Cultural & $\begin{array}{l}\text { É um tipo particular de atividade ligada com } \\
\text { práticas particulares; um campo particularmente } \\
\text { suscetível ser de multiníveis. Envolve fenômenos } \\
\text { complexos que se relacionam com as microativida- } \\
\text { des contidas no processo. O entendimento de ou- } \\
\text { tros elementos ligados às atividades é fundamen- } \\
\text { tal para a compreensão do que seja estratégia. }\end{array}$ & & & \\
\hline $\begin{array}{l}\text { Whittington } \\
\text { (1996), Whit- } \\
\text { tington (2003) }\end{array}$ & $\begin{array}{l}\text { As estratégias estão ligadas às praticas sociais e } \\
\text { não ao processo. O foco está nas rotinas e não } \\
\text { nas mudanças. Trata-se de uma crítica à escola de } \\
\text { planejamento. }\end{array}$ & & & \\
\hline
\end{tabular}

Fonte: Ampliado de NICOLAU, 2001.

\section{A estratégia enquanto prática}

A estratégia enquanto prática é a corrente teórica que busca recuperar a prática da estratégia da posição marginal identificada nas agendas contemporâneas de pesquisa. Nessa abordagem, na medida em que a estratégia se aproxima da prática, deixa de ser um atributo da organização para ser uma atividade, ou seja, aquilo que as pessoas fazem (WHITTINGTON et al., 2003; WHITTINGTON; JOHNSON; MELIN, 2004; JARZABKOWSKI, 2004). Tenta-se nessa abordagem estudar as microatividades, que normalmente são "invisíveis" às teorias estratégicas tradicionais, mas que podem levar a consequências significantes para a organização. Deve-se lembrar que aos estrategistas é designada essa responsabilidade e a consequência, a geração de novas estratégias (por exemplo, estratégia de eliminação de hábitos que gerem doenças, campanhas contra drogas, eliminação de determinado conceito público através de relações públicas). $\mathrm{O}$ autor valoriza a visão baseada na atividade (VBA) em detrimento da visão baseada em recursos (VBR), que advoga que os recursos e as capacitações acumuladas ao longo do tempo determinam as atividades, $o$ nível de custos ou diferenciação. Para Jarzabkowski (2004), a prática social é caracterizada pela recursividade, que é evidente nas escolhas que derivam da interação entre instituições sociais, organizações e atores. Como as firmas aparentam "realizar escolhas", de forma similar a recursividade aparentemente também está ligada às "melhores práticas". Entretanto, a convergência para as melhores práticas também pode estar associada a formas organizacionais inertes e à destruição da diferenciação estratégica entre competidores. Nessa teoria, embora exposta para contrapor o conceito tradicional de estratégia, a autora aborda o mesmo processo lógico usado por Mintzberg e Waters (1985) para lançar a abordagem sobre o surgimento de vários tipos de estratégias, nos quais eles, ao descrever o processo para explicar a formação de estratégias deliberadas a emergentes, tocam no cerne da solução do problema epistemológico, abordando uma nova perspectiva teórica onde até mesmo a prática é considerada estratégia. 
O estudo acerca de estratégias e práticas é histórico. Por exemplo, um dos primeiros usos do termo estratégia foi há pelo menos 3 mil anos, quando Sun Tzuo disse: "todos os homens podem ver as táticas pelas quais eu conquisto, mas o que ninguém consegue ver é a estratégia a partir da qual grandes vitórias são obtidas". Torna-se importante uma reflexão sobre isso e os termos clássicos sobre estratégia, conforme o Quadro 1. No Quadro notou-se a convergência de ideias no sentido de a estratégia incluir planos, metas, o futuro e ser explícita ou não. Nesse contexto, a "arte da guerra" pode incluir atividades que visem enganar os inimigos. Logo, a atividade em si, se for analisada, não estará refletindo a realidade. Uma estratégia deliberada pode incluir enganar o concorrente enquanto se executa outra estratégia para atingir certo objetivo. Em Safári de Estratégia, Mintzberg, Lampel e Ahsltrand (2000) apresentam a estratégia como ploy (truque) ou manobra específica que uma organização use para enganar um concorrente. A obra desses autores evidencia que é possível estudar e descrever as atividades, como visto aqui, até certo ponto. Esse ponto é o limite sociológico, que leva em conta as relações sociais e não o estudo do indivíduo.

Práticas institucionalizadas e estratégia planejada: há apenas um caminho?

Os estudos de Whittington, Johnson e Melin (2004) comparam o fenômeno da estratégia com uma história de Sherlock Holmes. Por outro lado, o sucesso sistemático dos museus foi difícil explicar. Para estes autores, etnografias de microatividades são provavelmente incompletas sem um alcance das práticas institucionalizadas que prevalecem num nível mais alto nas organizações. Assim, as atividades são ligadas às estratégias e o inverso.

Whittington, Johnson e Melin (2004) referem-se à lógica da ação para a formação da estratégia. 0 ponto de vista dele difere dos estudiosos de estratégia enquanto prática na questão metodológica, ou seja, a estratégia enquanto prática estuda a ação e Whittington, Johnson e Melin propõem o modelo de Weick (1969) contestando a rotinização porque ela pode desencorajar a orientação criativa. Nesta abordagem, a organização deve rastrear as estratégias realizadas e tentar entender os comportamentos da organização. $\mathrm{Na}$ abordagem a estratégia tem a ver com escolhas e vários processos de pensamento (MINTZBERG;
LAMPEL; AHSLTRAND, 2000), e não com as ações. As escolas prescritivas são duramente criticadas pelos autores, que argumentam que estas têm dominado a literatura sem apresentar perspectivas suficientes para o exército de formados em administração, a quem se pode atribuir o fracasso estratégico das organizações em que trabalham.

Há uma diferença entre uma ação pura e simples e uma ação gerada por um "atrito". A estratégia depende de elementos básicos que são usados no ataque, na defesa e em manobras. A criação da estratégia consiste em encontrar e executar novas combinações desses elementos (MINTZBERG; LAMPEL; AHSLTRAND, 2000).

\section{Metodologia da pesquisa}

0 presente ensaio foi desenvolvido a partir de uma revisão integrativa (integrativereview) que buscou ratificar algumas proposições e ao mesmo tempo encontrar subsídios para desenvolver um conteúdo relevante para as pesquisas acerca do tema estratégia. Esse método, de acordo com Neuman (1997), adequa-se no caso de o pesquisador buscar sintetizar o conhecimento atual sobre determinada disciplina ou tópico. 0 critério para a delimitação considerou os artigos e livros seminais na área de estratégia (PORTER, 1996; MINTZBERG, 1975; MINTZBERG; McHUGH, 1985). A partir dessa reunião e leitura de artigos, foram selecionados aqueles que apresentam argumentos mais substanciais sobre o tema escolhido. A partir das evidências destacadas no artigo, foram apresentadas as proposições.

\section{Resultados e conclusões}

Como ficou evidente nas páginas deste artigo, através dos dezoito trabalhos examinados que falam especificamente sobre estratégia, há atualmente que se considerar a existência de divergências e um lapso conceitual acerca do termo estratégia Whittington (2004 apud ABID, 2006) e de questões epistemológicas que envolvem os estudos relativos à área da estratégia enquanto prática. 0 que se observa com uma pesquisa literária sobre estas questões é uma tentativa de manter a guerra conceitual em vez de tentar-se chegar a um consenso benéfico para estudantes, pesquisadores e principalmente para as organizações, 
objeto central dos estudos em administração. 0 paradigma pode ofuscar a eficácia de pesquisas.

A estratégia enquanto prática parece aproximar-se do que Mintzberg chama de estratégia deliberada, ou seja, "um padrão realizado não era pretendido". As estratégias podem ser deliberadas, mas com posições e considerações de experiência de um grupo como emergente. Neste caso, a estratégia enquanto prática situa-se em antigas abordagens, considera etapas do processo que já foram estudadas, mas reveste-se de roupa nova. As dez escolas abordadas em Safári de Estratégia, segundo o autor, olham para o mesmo processo. A estratégia enquanto prática situa-se no processo, ligada à escola cognitiva, segundo o que se abordou aqui. A estratégia enquanto prática supõe e pressupõe a metodologia de estudo de microatividades estabelecidas ou rotinizadas, o que quebra o encantamento das escolas do planejamento que defendem a criatividade e a cognição no processo de formação da estratégia. Uma conclusão lógica pela quantidade de referenciais apresentados é que há teorias mais do que suficientes para as mesmas práticas. A necessidade latente e urgente é de convergência teórica.

Antes de concluir, torna-se necessário considerar uma questão fundamental de cunho sociológico, que explica mas não justifica o cenário atual, descrito acima, em relação às barreiras no campo da pesquisa. Se a estratégia enquanto prática está ligada à pesquisa de microatividades, torna-se necessária uma análise dos possíveis métodos de pesquisa. Quase invariavelmente, as investigações são limitadas em termos de escopo e unidade de análise. Outra limitação é a identificação de atividades estratégicas (WHITTINGTON, 2003), que exige aproximação com as atividades daqueles que desempenham a ação estratégica, pois a principal limitação dos estudos nessa área é a falta de credibilidade em torno da precisão do método adotado pelo pesquisador na captura dos processos e atividades estratégicas fundamentais. Salvato (2003) indica análise de dados secundários e entrevistas semiestruturadas como métodos de pesquisa. Regnér (2003) propõe a utilização do estudo de caso longitudinal retrospectivo múltiplo, que ocorre essencialmente por meio da análise de documentos, observação e entrevistas com avaliações de longos horizontes de tempo. Jarzabkowski (2005) sugere a realização de entrevistas, coleta de dados qualitativos históricos e observação não participante como métodos a serem empregados no trabalho de campo. Samra-Fredericks (2003) julga mais adequada a etnografia etnometodologicamente fundamentada, que conjuga análise de conversação e etnografia. Entretanto Balogun, Huff e Johnson (2003) defendem que, apesar de métodos etnográficos e de observação serem bastante atrativos para o estudo da estratégica enquanto prática, em se tratando de grandes corporações diversificadas, com unidades e áreas dispersas mundialmente, são necessários métodos mais flexíveis e de maior amplitude de investigação.

Considerando-se a abordagem interpretativa no estudo das organizações a partir da década de 1970, percebe-se a entrada num mundo ainda mais complexo de interações, relações e conflitos (WEICK, 1969). Nesta, as atividades organizacionais estão sujeitas à constante definição e redefinição devido à eclosão de interesses divergentes, competição profissional, rotatividade de profissionais e incertezas e a ordem social é produzida por meio de negociações e entendimentos implícitos, construídos por meio de experiências compartilhadas. 0 que sustenta a sociedade é um consenso parcial sobre como as coisas são percebidas e os significados que lhes são atribuídos, gerando padrões de interpretação, expressos em regras e em sistemas de crenças e valores - a realidade é socialmente construída. Essa visão contempla um arcabouço prescrito de padrões emergentes de interação, intermediados por esquemas interpretativos.

Por esse viés sociológico inevitável, a estratégia enquanto prática encontra uma barreira em relação à previsibilidade das ações e que os pesquisadores de várias disciplinas no estudo das organizações vejam invariavelmente que não há como se esquivar desse contexto. Por outro lado, o estudo das organizações não pode ser confundido com o estudo dos fatos sociais, cuja tarefa é da sociologia. Para a escola de cognição (MINTZBERG; LAMPEL; AHSLTRAND, 2000), toda ação implica numa tomada de decisão. A experiência dá forma ao saber e ao fazer, moldando assim a experiência subseqüente, onde os atores são autodidatas, num processo de interpretação do mundo que pode ser objetivo ou subjetivo, mas sempre por meio da cognição. Assim, não há como, através da ciência, interpretar esse processo. Seria especialmente útil saber não só como a mente distorce, mas também como ela é capaz, algumas vezes, de integrar informações diversas. Porque a despeito de todos os comportamentos estratégicos estranhos que ocorram, alguns gerentes conseguem dar enormes saltos de cognição. Surgem algumas perguntas: Qual a 
relação entre estratégia enquanto prática e a abordagem da escola de cognição? 0 que é mais importante estudar em administração: os processos mentais ou o processo das relações sociais? Há relação entre ação e tomada de decisão? E isso tem algo a ver com estratégia? Considere o comentário de Mintzberg e Walters (1985).

A maior parte das pesquisas sobre tomada de decisões partiu inicialmente não da decisão, mas sim da ação, como por exemplo, a compra de um computador ou de uma empresa. Elas então [as ações] assumiram a decisão: que um momento identificável de compromisso precedeu inevitavelmente a ação. Em outras palavras, se uma organização fez alguma coisa, ela deve ter decidido fazê-la anteriormente. A conclusão é que a decisão às vezes é uma elaboração artificial, psicológica, que imputa compromisso com a ação, ou qualquer compromisso que precede a ação pode ser vago e confuso.

Neste contexto, existe uma relação estreita e sequencial entre ação e tomada de decisão. Os modelos mentais interferem na ação e no processo estratégico. Falando de processo, voltamos a uma pergunta de Mintzberg, Lampel e Ahsltrand (2000): "Será que as escolas falam de processos diferentes ou partes diferentes do mesmo processo?" Para estes autores, é necessário combinar vários aspectos das diferentes escolas, porque o que se precisa é de boas práticas, e não de teoria organizada. Assim ele vê de forma positiva a aparição de vários híbridos teóricos, conforme abordamos neste artigo.

\section{Referências}

AKTOUF, O. Governança e pensamento estratégico: uma crítica a Michael Porter. Revista de Administração de Empresas, v. 42, n. 3, p. 43-53, 2002.

ABID, G. Os componentes informacionais e seus efeitos como recurso competitivo nas cooperativas paranaenses. 2006.161 f. Dissertação (Mestrado em Administração)Universidade Federal do Paraná, Curitiba, 2006.

BALOGUN, J.; HUFF, A. S.; JOHNSON, P. Three responses to the methodological challenges of studying strategizing. Journal of Management Studies, v. 40, n. 1, p. 197-224, 2003.
DENIS, J.; LANGLEY, A.; ROULEAU, L. The power of numbers in strategizing. Strategic Organization, v. 4, n. 4, p. 349-377, 2006.

DOZ, Y. L.; PRAHALAD, C. K. Quality of management: an emerging source of global competitive advantage? In: HOOD, N.; VAHLNE, J. E. (Ed.). Strategies in global competition. London: Croom-Helm, 1988. p. 345-369.

DOZ, Y. L.; PRAHALAD, C. K. Managing DMNCs: a search for a new paradigm. Strategic Management Journal, v. 12, special issue, p. 145-164, 1991.

JARZABKOWSKI, P. Strategic practices: an activity theory perspective on continuity and change. Journal of Management Studies, v. 40, n. 1, p. 23-55, 2003.

JARZABKOWSKI, P. Strategy as practice: recursiveness, adaptation, and practices-in-use. Organization Studies, v. 25, n. 4, p. 529-560, 2004.

JARZABKOWSKI, P. Strategy as practice: an activity-based approach. London: Sage, 2005.

JARZABKOWSKI, P.; BALOGUN, J.; SEIDL, D. Strategizing: the challenges of a practice perspective. Human Relations, v. 60, n. 1, p. 15-27, 2007.

MINTZBERG, H. The manager's job: folklore and fact. Harvard Business Review, v. 53, n. 4, p. 49-62, 1975.

MINTZBERG, H. Ascensão e queda do planejamento estratégico. Porto Alegre: Bookman, 2004.

MINTZBERG, H.; LAMPEL, J.; AHSLTRAND, B. Safári de estratégia: um roteiro pela selva do planejamento estratégico. Porto Alegre: Bookman, 2000.

MINTZBERG, H.; McHUGH, A. Strategy formation in an adhocracy. Administrative Science Quarterly, v. 30, n. 2, p. 160-197, 1985.

MINTZBERG, H.; WATERS, J. A. Of strategies, deliberate and emergent. Strategic Management Journal, v. 6, n. 3, p. 257-272, 1985.

NEUMAN, W. L. Social research methods: qualitative and quantitative approaches. 3rd ed. Boston: Allyn and Bacon, 1997.

NICOLAU, I. O conceito de estratégia. Campo Grande: Instituto Para o Desenvolvimento da Gestão Empresarial, 2001. Disponível em: <http://antonio-fonseca.com Unidades $\% 20$ Curriculares/3-Ano/Planeamento $\% 20 \mathrm{e} \% 20$ Gestao\%20Estrategica/conceito_20estrategia $\% 20$ \%281\%29.pdf>. Acesso em: 14 fev. 2008. 
PORTER, M. What is strategy? Harvard Business Review, p. 61-78, 1996.

REGNÉR, P. Strategy creation in the periphery: inductive versus deductive strategy making. Journal of Management Studies, v. 40, n. 1, p. 57-82, 2003.

RITZER, G. Sociology: a multi-paradigm science. The American Sociologist, v. 10, n. 3, p. 156-167, 1975.

SALVATO, C. The role of micro-strategies in the engineering of firm evolution. Journal of Management Studies, v. 40, n. 1, p. 83-108, 2003.

SAMRA-FREDERICKS, D. Strategizing as lived experience and strategists' everyday efforts to shape strategic direction. Journal of Management Studies, v. 40, n. 1, p. 141174,2003

WEICK, K. The social psychology of organizing. Reading, Mass: Addison-Wesley, 1969.

WHITTINGTON, R. The work of strategizing and organizing: for a practice perspective. Strategic Organization, v. 1 , n. 1 , p. $117-125,2003$.
WHITTINGTON, R. Completing the practice turn in strategy research. Organization Studies, v. 27, n. 5, p. 613-634, 2006.

WHITTINGTON, R. et al. Taking strategy seriously. Journal of Management Inquiry, v. 12, n. 4, p. 396-409, 2003.

WHITTINGTON, R.; JOHNSON, G.; MELIN, L. The emerging field of strategy practice: some links a trap, a choice and a confusion. In: EUROPEAN GROUP FOR ORGANIZATIONAL STUDIES, 20., 2004, Sovenia. Colloquium... Sovenia: EGOS, 2004.

Recebido: 10/06/2011

Received: 06/10/2011

Aprovado: 15/08/2011

Approved: 08/15/2011 